\title{
Article
}

\section{Modified cassava starch/poly(vinyl alcohol) blend films plasticized by glycerol: Structure and properties}

Boonsuk, Phetdaphat, Sukolrat, Apinya, Kaewtatip, Kaewta, Chantarak, Sirinya, Kelarakis, Antonios and Chaibundit, Chiraphon Available at http://clok.uclan.ac.uk/31353/

Boonsuk, Phetdaphat, Sukolrat, Apinya, Kaewtatip, Kaewta, Chantarak, Sirinya, Kelarakis, Antonios ORCID: 0000-0002-8112-5176 and Chaibundit, Chiraphon (2021) Modified cassava starch/poly(vinyl alcohol) blend films plasticized by glycerol: Structure and properties. Journal of Applied Polymer Science, 137 (26). ISSN 0021-8995

It is advisable to refer to the publisher's version if you intend to cite from the work. http://dx.doi.org/10.1002/app.48848

For more information about UCLan's research in this area go to http://www.uclan.ac.uk/researchgroups/ and search for <name of research Group>.

For information about Research generally at UCLan please go to http://www.uclan.ac.uk/research/

All outputs in CLoK are protected by Intellectual Property Rights law, including Copyright law. Copyright, IPR and Moral Rights for the works on this site are retained by the individual authors and/or other copyright owners. Terms and conditions for use of this material are defined in the policies page.

\section{CLoK}

Central Lancashire online Knowledge www.clok.uclan.ac.uk

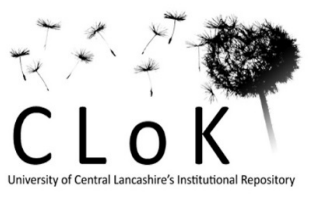


Modified cassava starch/poly(vinyl alcohol) blend films plasticized by glycerol: Structure and properties

Phetdaphat Boonsuk, ${ }^{1}$ Apinya Sukolrat,${ }^{2}$ Kaewta Kaewtatip, ${ }^{1}$ Sirinya Chantarak, ${ }^{1}$ Antonios Kelarakis, ${ }^{3}$ Chiraphon Chaibundit ${ }^{1, *}$

${ }^{1}$ Department of Materials Science and Technology, Faculty of Science, Prince of Songkla University, Hat Yai, Songkhla, Thailand, 90110.

${ }^{2}$ Scientific Equipment Center, Prince of Songkla University, Hat Yai, Songkhla, Thailand, 90110.

${ }^{3}$ School of Physical Sciences and Computing, University of Central Lancashire, Preston PR1 2HE, UK. 


\begin{abstract}
We report a systematic investigation on the structure-property relationships in glycerol-plasticized poly(vinyl alcohol) (PVA)/cassava starch blends prepared via solution casting. In particular, PVA mixed with native, low-oxidized, high-oxidized and pregelatinized cassava starches were characterized by means of SEM, XRD, FTIR, thermal analysis and mechanical testing and the immiscible systems were received. Burial tests over a period of several days suggested the preferential degradation of the starch and glycerol component (as indicated by the absence of FTIR signatures of those components) and the amorphous phase of PVA (as indicated by the enhanced crystallinity index of the degraded samples). The rheological properties of the blends seem to dictate their morphological characteristics that, in turn, have a profound impact on their mechanical properties. In that sense, the study highlights promising strategies for the development of a new family of polymeric materials that combine their biodegradable nature within superior mechanical properties.
\end{abstract}

Keywords: PVA; modified starch; tensile; biodegradation; morphology 


\section{Introduction}

Poly(vinyl alcohol) (PVA) is the largest synthetic water-soluble, ${ }^{1}$ semi-crystalline, and moderately biodegradable polymer. ${ }^{2}$ Commercial PVA is made by the hydrolysis of poly(vinyl acetate) and it is approximately atactic. ${ }^{3}$ PVA with a high molar mass of $10^{6} \mathrm{~g} / \mathrm{mol}$ can be degraded by the soil bacteria, Pseudomonads. ${ }^{4}$ However, PVA has drawbacks of high $\operatorname{cost}^{5}$ and slow anaerobic degradation. ${ }^{6}$ The degradation rate strongly depends on the quantity of residual acetate groups. ${ }^{7}$ The low biodegradation rate of PVA has encouraged research into economically viable ways of blending PVA with biodegradable polymers such as $\operatorname{starch}^{8,9}$ and protein. ${ }^{10}$

Starch has proved to be the most promising natural material to blend with PVA. ${ }^{9}$ It is an abundant renewable resource, ${ }^{11}$ and the varieties of starch studied in polymer blends have included: potato starch, ${ }^{12}$ corn starch,${ }^{11,13}$ wheat starch,,${ }^{14-15}$ Amaranthus cruentus flour, ${ }^{16}$ pea starch,,${ }^{9,17}$ and oxidized cassava starch. ${ }^{18}$ Oxidized starch is produced by reaction with an oxidizing agent under controlled temperature and $\mathrm{pH} .{ }^{19-21}$ Hypochlorite oxidation is a common method of oxidizing starch. ${ }^{20}$ During the oxidation reaction, hydroxyl groups on starch molecules are oxidized to carbonyl and carboxyl groups, determined by the titration method. ${ }^{19}$ The reaction improves the starch paste by degrading starch molecules, which reduces the viscosity of the starch. ${ }^{22}$ Research into oxidized starch blended with polymers has yielded oxidized banana starch/PVA, ${ }^{23}$ oxidized cassava starch/polyacrylamide and oxidized cassava starch/PVA. ${ }^{18}$ Therefore, oxidized starch could be an alternative way of producing biodegradable films.

An alternative modification of starch is pre-gelatinization by a cooking and subsequent drying. These processes resulted in the complete structural disintegration of starch granules and the disappearance of birefringence properties. ${ }^{24}$ Gelatinization disrupts the molecular order in starch granules and produce changes, such as granular swelling, native 
crystalline melting and loss of birefringence. The properties of pre-gelatinized starch are increased solubility and capacity to swell, form paste, high viscosity, smooth texture and cold water solubility. ${ }^{25}$ It was reported that the solubility of pre-gelatinized starch was lower than native starch whereas the swelling capacity was higher. ${ }^{26}$ Partially pre-gelatinized starch contains soluble and insoluble fractions, but fully pre-gelatinized starch is extremely soluble in cold water. ${ }^{27}$

Although starch/PVA blend polymers have poor mechanical properties, ${ }^{3,5}$ problems of rigidity and poor workability have been overcome by the use of plasticizers that improve flexibility and ductility. Effective plasticizers of starch/PVA blends are glycerol, ${ }^{13-15}$ sorbitol, ${ }^{28}$ and ascorbic acid. ${ }^{12}$ However, Chaléat et al. reported the occurrence of phase separation in plasticized starch/PVA blends, as confirmed by dynamic mechanical thermal analysis and solid-state ${ }^{13} \mathrm{C}$ NMR spectroscopy. ${ }^{29}$ Characterization by dynamic mechanical thermal analysis and solid-state ${ }^{13} \mathrm{C}$ NMR spectroscopy confirmed phase separation in all blend compositions. ${ }^{29}$ The immiscibility of polymer blends produced a variety of different morphologies, including dispersed droplets, ${ }^{30}$ fibers, ${ }^{31}$ lamellae, ${ }^{32}$ and co-continuous phases (systems that possess two continuously percolated and interpenetrated phases). ${ }^{33} \mathrm{Co}-$ continuous blends possess two continuously percolated and interpenetrated phases. The morphologies of polymer blends depended upon the composition, processing condition, ${ }^{34}$ viscosity ratio, interfacial tension, shear rate, and phase dimension. ${ }^{35}$

Processing PVA by melt-mixing is challenging given that its high melting point (from 224 to $246^{\circ} \mathrm{C}$ ) falls within a temperature range where thermal degradation takes place. Therefore, PVA has frequently been processed in solution form, ${ }^{36}$ and the preparation of PVA/starch blend films by the solution casting technique has been reported in the literature. ${ }^{1-}$ 3,12-18,37,38 Since this method could produce a uniform thickness from a quick, inexpensive, 
and low-temperature process, it is a suitable procedure for a lab-scale investigation ${ }^{39}$ even though it presents certain challenges for large-scale applications. ${ }^{40}$

In this work, films were produced by a casting solution method, from unblended and blended preparations of PVA and native and modified cassava starches. The aim of this work is to report a systematic investigation of the structure-property relationships in a family of glycerol-plasticized PVA/starch blends. Our results indicate that these types of materials can show reasonable levels of mechanical strength, stemming from the PVA phase, coupled with phase separation due to the nature of the starch and PVA content.

\section{Experimental}

\subsection{Materials}

Native cassava starch (NCS) (PD15037), food grade low-oxidized cassava starch (LCS) (PD15038), food grade high-oxidized cassava starch (HCS) (PD15039), and pregelatinized cassava starch (PCS) (PD10370) were from Siam Modified Starch, Ltd., Thailand. Poly(vinyl alcohol) (PVA) (MW 89,000-90,000; 99\% hydrolysis; Sigma-Aldrich, St. Louis), and glycerol (Gly) (Sigma-Aldrich, Steinheim, Germany) were used as received.

\subsection{Preparation of blend films}

A series of films, all plasticized with a constant $3 \mathrm{~g}$ of glycerol, was produced by a solution casting method. Using the compositions listed in Table 1, plasticized films were fabricated of unblended PVA, unblended starch, and PVA/starch blends using four types of cassava starch. As an example, the 5PVA/5NCS/Gly blend film was prepared by dissolving 5 $\mathrm{g}$ of PVA in $100 \mathrm{~mL}$ of water at $95{ }^{\circ} \mathrm{C}$ using a kitchen mixer (Electrolux, EHM2000, speed no. 1). Separately, $5 \mathrm{~g}$ of native cassava starch were dissolved in $100 \mathrm{~mL}$ of water. When the cassava starch was dissolved, $3 \mathrm{~g}$ of glycerol were added and the mixture was stirred for 30 min. The PVA solution was then added to the cassava starch and glycerol solution and the 
whole was stirred for $30 \mathrm{~min}$ at $95{ }^{\circ} \mathrm{C}$. The total volume was maintained by adding water. To remove bubbles and small amount of undissolved polymers $(<1 \mathrm{wt} \%)$, the solution was filtered through a kitchen sieve onto a polystyrene plate $(20 \mathrm{~cm} \times 29 \mathrm{~cm})$ and left overnight at room temperature. The next day, the solution was dried in an oven at $60{ }^{\circ} \mathrm{C}$ for $24 \mathrm{~h}$.

Table 1 Compositions of PVA, cassava starch, and PVA/cassava starch blend films.

\begin{tabular}{lcccc}
\hline Sample & PVA $(\mathrm{g})$ & Starch $(\mathrm{g})$ & Glycerol $(\mathrm{g})$ & Water $(\mathrm{mL})$ \\
\hline PVA/Gly & 10 & 0 & 3 & 200 \\
Starch/Gly & 0 & 10 & 3 & 200 \\
\hline 3PVA/7starch/Gly & 3 & 7 & 3 & 200 \\
5PVA/5starch/Gly & 5 & 5 & 3 & 200 \\
7PVA/3starch/Gly & 7 & 3 & 3 & 200 \\
\hline
\end{tabular}

\subsection{Characterization}

Fourier-transform infrared spectroscopy (FTIR). The FTIR spectra of the films were recorded in the frequency range of 600 to $4000 \mathrm{~cm}^{-1}$ on a Bruker Tensor 27 Fourier transform infrared spectrometer in attenuated total reflectance (ATR) mode using an accessory with a diamond crystal. Films were kept in a desiccator prior to testing. For each spectrum, 64 consecutive scans were recorded at a resolution of $4 \mathrm{~cm}^{-1}$. Both sides of the blend films were scanned and three data points were collected from each side.

Rheometry. Solutions of starch and PVA in glycerol were prepared by dissolving $10 \mathrm{~g}$ of starch or PVA with $3 \mathrm{~g}$ of glycerol in $200 \mathrm{~mL}$ water. Two hours after preparation, rheological measurements were carried out using a Discovery HR-2 Hybrid rheometer (TA Instrument) with $22 \mathrm{~cm}^{3}$ sample. Concentric cylinders (DIN Peltier Steel-111204) were used 
for all the samples. The apparent viscosity of the solution was measured at shear rates of 10 to $1,000 \mathrm{~s}^{-1}$ at $30^{\circ} \mathrm{C}$.

$X$-ray diffraction (XRD). Samples (air side) were analyzed using a Phillips diffractometer (Model X'Pert MDI) at a scanning rate of $3 \%$ min with $C u K \alpha$ radiation $(\lambda=$ $1.5410 \AA$ ) operating at $40 \mathrm{kV}$ and $30 \mathrm{~mA}$. The scanning range of $2 \theta$ was from 5 to $90^{\circ}$. The samples were determined within 1.5 months of their preparation.

Differential scanning calorimetry (DSC). Thermal properties of the films were characterized with NETZSCH apparatus (DSC 200F3). The films were kept in the desiccator prior to testing. The sample, in an aluminum pan, was initially cooled to $0^{\circ} \mathrm{C}$. It was then heated to $250^{\circ} \mathrm{C}$, cooled from 250 to $0^{\circ} \mathrm{C}$ and then heated again from 0 to $250^{\circ} \mathrm{C}$. The cooling and heating rates were $10^{\circ} \mathrm{C} \mathrm{min}^{-1}$.

Mechanical properties. The specimens were cut according to ASTM standard D638-03, Type $\mathrm{V}$ (width $=3.18 \mathrm{~mm}$, distance between grip $=25 \mathrm{~mm}$, and film thickness $=0.18+0.02$ $\mathrm{mm})$. Determination of the mechanical properties of the film was carried out with a Universal Testing Machine (Instron 3365) equipped with a $100 \mathrm{~N}$ load cell and operated at a cross-head speed of $20 \mathrm{~mm} / \mathrm{min}$. The samples were equilibrated for 7 days at $75 \%$ relative humidity $(\mathrm{RH})$ before testing. The relative humidity of the tropical countries is about $65-85 \%$, therefore, this equilibrating condition resembles the real situation. The measurements were taken at $25^{\circ} \mathrm{C}$ and ten specimens were determined per formulation. Statistical comparisons on the tensile strength and elongation at break were performed using one-way analysis of variance (ANOVA) followed by post hoc analysis with SPSS statistic software at the 5\% significance level $(\alpha=0.05)$ to determine the effect of PVA content in the blends.

Morphological studies. The morphologies of non-degraded and degraded films were determined using SEM (SEM-Quanta 400). Cryo-fracture samples were immersed in liquid nitrogen before fracturing. Some degraded films were cut with scissors to enable observation. 
All specimens were coated with a thin layer of gold. To obtain the degraded films, a soil burial test was carried out indoors using a procedure modified from Yoon et al. ${ }^{12}$ Briefly, the samples were cut into squares $15 \mathrm{~mm} \times 15 \mathrm{~mm}$, dried in an oven at $60^{\circ} \mathrm{C}$ for $24 \mathrm{~h}$, weighed, and buried at a depth of $5 \mathrm{~cm}$ in soil from a flower nursery in separate $500 \mathrm{~mL}$ cups. $\mathrm{RH}$ and air temperature were $66 \pm 4 \%$ and $29 \pm 1^{\circ} \mathrm{C}$. Six specimens were tested per formulation. The soil was watered with $10 \mathrm{~mL}$ every other day. To keep soil weight constant at around $265 \pm 3$ $\mathrm{g}$, care was taken to avoid adding excess of water that could drain through the hole at the bottom of the cup. Samples were buried in soil for 15 and 30 days, after which the degraded starch sheets were taken carefully from the soil and gently and quickly washed with water using a paint brush to remove soil. The degraded starch sheets were dried at $60^{\circ} \mathrm{C}$ for $24 \mathrm{~h}$. The weight losses of the degraded starch samples were calculated using the following equation:

$$
\text { Weight loss }(\%)=\left(w_{0}-w_{\mathrm{d}}\right) \times 100 / w_{0}
$$

where $w_{0}$ and $w_{\mathrm{d}}$ were the weight of the dried sample before and after soil burial, respectively.

\section{Results and discussion}

\subsection{Morphology of starches}

The SEM micrograph of granules of unmodified NCS (Figure 1(a)) show smooth spheres with a single facet. ${ }^{41}$ The LCS granules (Figure 1(b)) present a rough surface and some smaller particles. The granules of HCS (Figure 1(c)) present a smooth surface, similar to NCS, but particles are smaller than NCS. Both LCS and HCS granules were damaged and fractured, which contributed to the rough surface of LCS and the smaller size and irregular shape of both LCS and HCS granules. The facets of NCS and HCS granules, indicated by 
arrows (Figure 1(a) and (c)), present smooth surfaces, whereas the facets on LCS granules (Figure 1(b)) show rough surfaces. The SEM micrograph of PCS (Figure 1(d)) reveals irregular flakes rather than granules, ${ }^{24}$ indicating that the granular structure of starch had been completely destroyed by the gelatinization process. ${ }^{42}$ The size of PCS was bigger than granules of $\mathrm{NCS}^{26}$
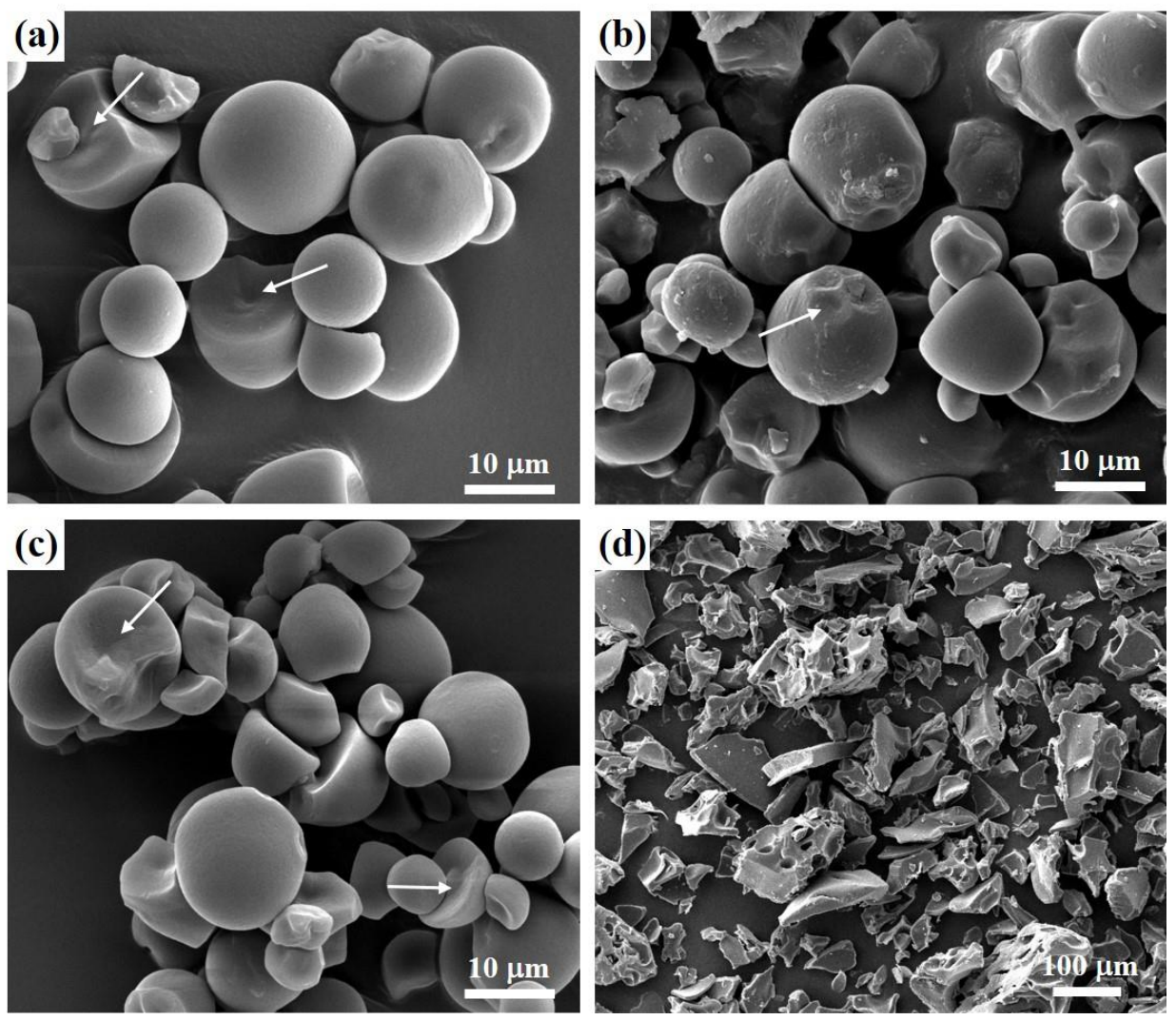

Figure 1. SEM micrographs of (a) NCS, (b) LCS, and (c) HCS at 2,000× magnification, and

(d) PCS at $150 \times$ magnification.

\subsection{Rheology of PVA and starch in glycerol solutions}

In the rheological study, solutions of NCS, LCS, HCS, PCS and PVA were prepared in glycerol. The apparent viscosity ( $\eta_{\text {app }}$ ) of all systems was plotted $v s$ shear rate. The $\eta_{\text {app }}$ of NCS, LCS, and PCS in glycerol solutions decreased with increasing shear rate (Figure 2(a)).

This result indicated a typical shear-thinning or pseudoplastic behavior. ${ }^{43,44}$ The viscosity of a 
liquid is a function of the inter-molecular forces restricting molecular motion. ${ }^{44}$ The decrease in $\eta_{\text {app }}$ with increasing shear rate suggests that inter-molecular resistance to flow was reduced by disentanglement of long chain molecules. Moreover, highly solvated particles in the medium may have been progressively sheared away as shear rate increased, resulting in a reduction in the size of the particles and hence a reduction in $\eta_{\mathrm{app} .}{ }^{45}$ The $\eta_{\text {app }}$ values of NCS and LCS in glycerol solution were much higher than the $\eta_{\text {app }}$ of HCS in glycerol solution. The oxidation process that produces oxidized starch was reported to depolymerize amylose and amylopectin chains ${ }^{46}$ and as a result, the molecular weight and viscosity of oxidized starch decreased..$^{47}$ The results of plotting $\eta_{\text {app }} v s$ shear rate indicate that HCS had the lowest molecular weight of the starches tested, and NCS had the highest molecular weight. The entangled condition of NCS chains increased $\eta_{\text {app }}$ at low shear rates.
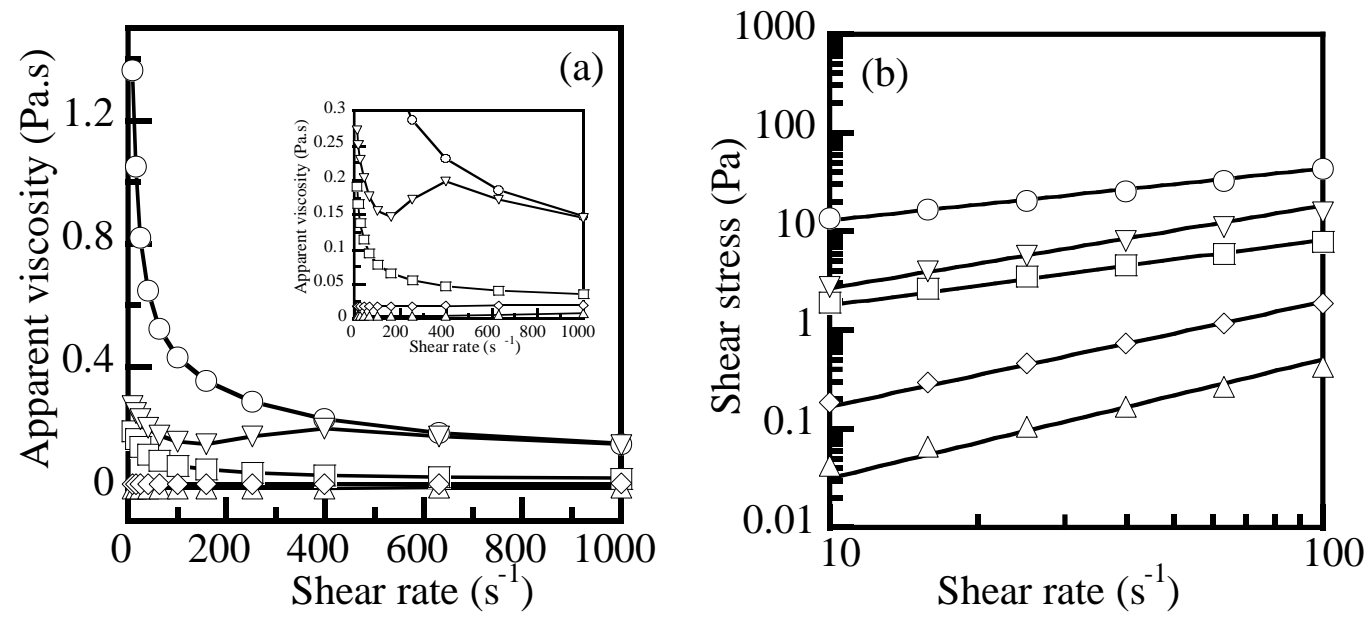

Figure 2. Rheological plots of (a) apparent viscosity $v s$ shear rate at $30^{\circ} \mathrm{C}$ (The inset shows low apparent viscosity.) and (b) flow curves in double logarithmic scale at $30^{\circ} \mathrm{C}$. (O) NCS, $(\square)$ LCS, $(\triangle)$ HCS, $(\nabla)$ PCS, and $(\diamond)$ PVA in glycerol solutions. 
PCS in glycerol solution consisted of a soluble and insoluble or gel fraction which were both visible during the preparation of the solution. The low $\eta_{\text {app }}$ of PCS in glycerol solution was plotted and is shown in the inset in Figure 2(a). At shear rates between 10 and $150 \mathrm{~s}^{-1}$, shear thinning behavior occurred, but at shear rates between 150 and $400 \mathrm{~s}^{-1}$, shear thickening behavior was observed. The transition from shear thinning to shear thickening took place at a shear rate of $150 \mathrm{~s}^{-1}$. As the shear rate exceeded $400 \mathrm{~s}^{-1}$, shear thinning again occurred and continued to the maximum shear rate of the test. The shear thickening was observed between 150 and $400 \mathrm{~s}^{-1}$ and was likely due to the formation of an interconnected, jammed network of large clusters ${ }^{48}$ probably from the gel fraction of PCS.

Flow curves were plotted of log shear stress versus log shear rate for all systems (Figure 2(b)). Shear stress increased with shear rate. The viscosity of polymer solutions is generally described by the power law model. The relationship between shear stress $(\tau)$ and shear rate $(\gamma)$ can be expressed by the following equation:

$$
\tau=k \gamma^{n}
$$

where $k$ is a consistency index and $n$ is a flow behavior index. The slope of the curve that provided the pseudoplasticity index $(n)$ of each solution was evaluated from the trend line. ${ }^{34}$ The respective $n$ values of NCS, LCS, HCS, PCS and PVA, all in glycerol solutions at $30^{\circ} \mathrm{C}$, were $0.52\left(\mathrm{R}^{2}=0.999\right), 0.66\left(\mathrm{R}^{2}=0.982\right), 1.20\left(\mathrm{R}^{2}=0.999\right), 0.84\left(\mathrm{R}^{2}=0.986\right)$, and $1.06\left(\mathrm{R}^{2}\right.$ $=0.987)$. The behaviors of HCS $(n=1.20)$ and PVA $(n=1.06)$ in glycerol solutions were non-Newtonian and Newtonian, respectively. Valencia et al. studied cassava starch in glycerol solution using the power law. ${ }^{49}$ The results indicated pseudoplastic behavior with $n$ $=0.59\left(\mathrm{R}^{2}=0.99\right)$ at $30^{\circ} \mathrm{C}$. The $n$ value of PCS in glycerol solution was higher than that of 
NCS in glycerol solution, indicating that PCS was less pseudoplastic. ${ }^{50}$ Other starches in glycerol solutions exhibited pseudoplastic behavior with $n$ values less than unity. ${ }^{51}$

\subsection{XRD of the films}

The XRD patterns of LCS and HCS granules are similar to the patterns for NCS granules (Figure 3(a)-(c)). In a previous work, the diffraction patterns of all starch granules showed peaks at $2 \theta \approx 15.2,17.2,17.9$, and $23^{\circ},{ }^{41}$ suggesting that oxidation occurred in the amorphous lamellae of LCS and HCS. However, Klein et al. reported that the ozone oxidation of cassava starch took place not only in the amorphous lamellae but also in the semi-crystalline region. ${ }^{41}$ The broad peak in the diffraction pattern of PCS flakes (Figure $3(d))$ indicates the loss of crystalline structure during the gelatinization process. ${ }^{42}$

The diffraction peaks of PVA/Gly film $(10 / 0)$ are located at $2 \theta \approx 11.4^{\circ}, 19.6^{\circ}, 3,52$ and $40.7^{\circ},{ }^{2}$ and the shoulder peak, located at $2 \theta \approx 22.6^{\circ}$, indicates that PVA was atactic. ${ }^{52}$ The presence of the main diffraction peak $2 \theta \approx 19.6^{\circ}$ in the patterns of all the PVA/starch/Gly blend films suggests that the crystalline structure of PVA was not affected by the added starches. ${ }^{3}$ In the diffraction patterns of all PVA/starch/Gly blends, most of the peaks attributed to starch were absent due to the destruction of the crystalline structure of starch granules as a result of gelatinization during the blending process ${ }^{9}$ and the diffraction patterns were close to that of PVA. 

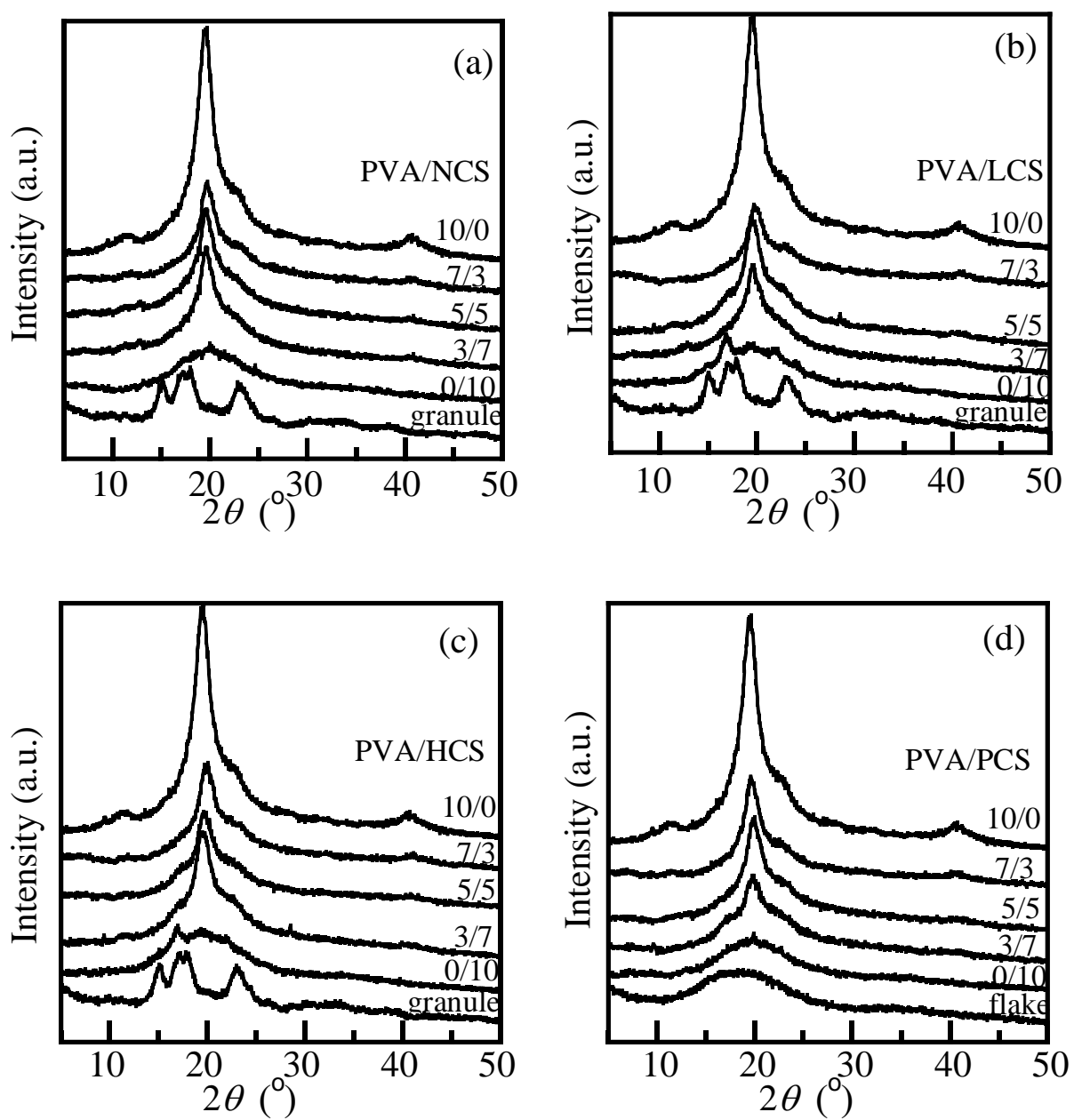

Figure 3. XRD patterns of (a) NCS granule, PVA/NCS/Gly blends and PVA/Gly film, (b) LCS granule, PVA/LCS/Gly blends and PVA/Gly film, (c) HCS granule, PVA/HCS/Gly blends and PVA/Gly film, and (d) PCS flake, PVA/PCS/Gly blends and PVA/Gly film: the ratio of $\mathrm{PVA} /$ starch is indicated above each spectrum.

\subsection{FTIR structure of the films}

The FTIR assignments of PVA, starch, PVA/Gly, and starch/Gly films are shown in Table S1 in the Supporting Information. For PVA/Gly films, peaks located at 3264, $2938 / 2909,1651,1236$, and $1142 / 1090 \mathrm{~cm}^{-1}$ were attributed to the $-\mathrm{OH}$ stretching vibration, ${ }^{2,9}$ the $-\mathrm{CH}_{2}$ stretching vibration, ${ }^{2,9}$ the $-\mathrm{OH}$ bending of bound water, ${ }^{2}$ the $-\mathrm{CH}_{2} \mathrm{OH}$ (side chain) related mode, ${ }^{53}$ and the $\mathrm{C}-\mathrm{O}$ stretching in $\mathrm{C}-\mathrm{O}-\mathrm{H}$, respectively. Both PVA and PVA/Gly film showed similar absorption peaks. 
The peaks of starch/Gly film located between 3280 and $3294 \mathrm{~cm}^{-1}, 990$ and $994 \mathrm{~cm}^{-1}$, and 759 and $760 \mathrm{~cm}^{-1}$ were attributed to the $-\mathrm{OH}$ stretching vibration, ${ }^{2,9}$ the $\mathrm{C}-\mathrm{O}$ stretching in the $\mathrm{C}-\mathrm{O}-\mathrm{C}$ groups $^{9}$ in the glycosidic linkage ${ }^{54}$ and the $\mathrm{C}-\mathrm{O}$ bending in the $\mathrm{C}-\mathrm{O}-\mathrm{C}$ groups in the anhydrous glucose ring, ${ }^{9}$ respectively. The remaining FTIR assignments of starch/Gly were similar to those of PVA/Gly. Both starch and starch/Gly films showed similar absorption peaks. The FTIR assignments of starch in native and oxidized cassava starch films were similar and these results agreed with research reported by Klein et al.. ${ }^{41}$

Our work is the first to study the structure of both sides of the blend films prepared by the solution casting method. Regarding the PVA/starch/Gly films, the position of peaks in spectra obtained from the air side differed from those of the bottom side that was in contact with polystyrene plate during casting (Table S2-S3 in the Supporting Information). On the air side, peaks attributed to the - $\mathrm{OH}$ stretching vibration were located between 3264 and 3288 $\mathrm{cm}^{-1}$, peaks attributed to the $\mathrm{C}-\mathrm{O}$ stretching in the C-O-C groups in the glycosidic linkage were located between 991 and $1002 \mathrm{~cm}^{-1}$, and peaks attributed to the $\mathrm{C}-\mathrm{O}$ bending in the C-OC groups in the anhydrous glucose ring were located between 758 and $761 \mathrm{~cm}^{-1}$. At higher PVA content (7PVA/3starch/Gly), the -OH stretching peak was located close to the -OH peak of PVA and the peaks of the C-O stretching in the glycosidic linkage and bending in the anhydrous glucose ring were not present. On the bottom side, peaks attributed to the $-\mathrm{OH}$ stretching vibration were located between 3272 and $3286 \mathrm{~cm}^{-1}$ and peaks of the C-O stretching in the glycosidic linkage and bending in the anhydrous glucose ring were present between 994 and $996 \mathrm{~cm}^{-1}$ and 756 and $759 \mathrm{~cm}^{-1}$, respectively, for all compositions of PVA/starch/Gly blends. In the FTIR spectra of blend films scanned on the bottom side, the peaks of PVA and starch were located in the same place.

The weight loss due to degradation of PVA/Gly, starch/Gly, and PVA/starch/Gly blend films was determined after burial in soil for 15 and 30 days. The data are shown in 
Table S4 and plotted in Figure S1 in the Supporting Information. Since glycerol and starch were easily degraded by microorganisms in the environment, ${ }^{55}$ the evaluation of the degradation based on weight loss is of practical use.

Films degraded by burial in soil for 30 days were analyzed by FTIR and their assignments from scanning air and bottom sides are shown in Table S5 and S6 in the Supporting Information. Peaks were similar in spectra of both air and bottom sides. FTIR spectra of non-degraded starch/Gly films between 1800 and $600 \mathrm{~cm}^{-1}$ (Figure 4(a)) show the $\mathrm{C}-\mathrm{O}$ stretching and bending in the $\mathrm{C}-\mathrm{O}-\mathrm{C}$ groups of starch. The FTIR peaks of degraded PVA/Gly films differ considerably between 1200 and $900 \mathrm{~cm}^{-1}$ from those of non-degraded PVA/Gly films (Figure 4(b)).

FTIR spectra of degraded blend films buried in soil for 15 days are presented in Figure S2 in the Supporting Information. The peaks around 994 and $760 \mathrm{~cm}^{-1}$ attributed to the $\mathrm{C}-\mathrm{O}$ stretching and bending in the $\mathrm{C}-\mathrm{O}-\mathrm{C}$ groups of starch are not present in the spectra of most degraded blend films. Their absence suggests that starch in the samples was completely degraded. However, these peaks were still present in the spectra of degraded 3PVA/7NCS/Gly, 3PVA/7LCS/Gly and 3PVA/7HCS/Gly blend films buried in soil for 15 days (Figure S2(a)-(c)) and of degraded 3PVA/7NCS/Gly blend films buried in soil for 30 days (Figure 4(c)). The persistence of these peaks is due to incomplete removal of the initially high starch content in these blends. 

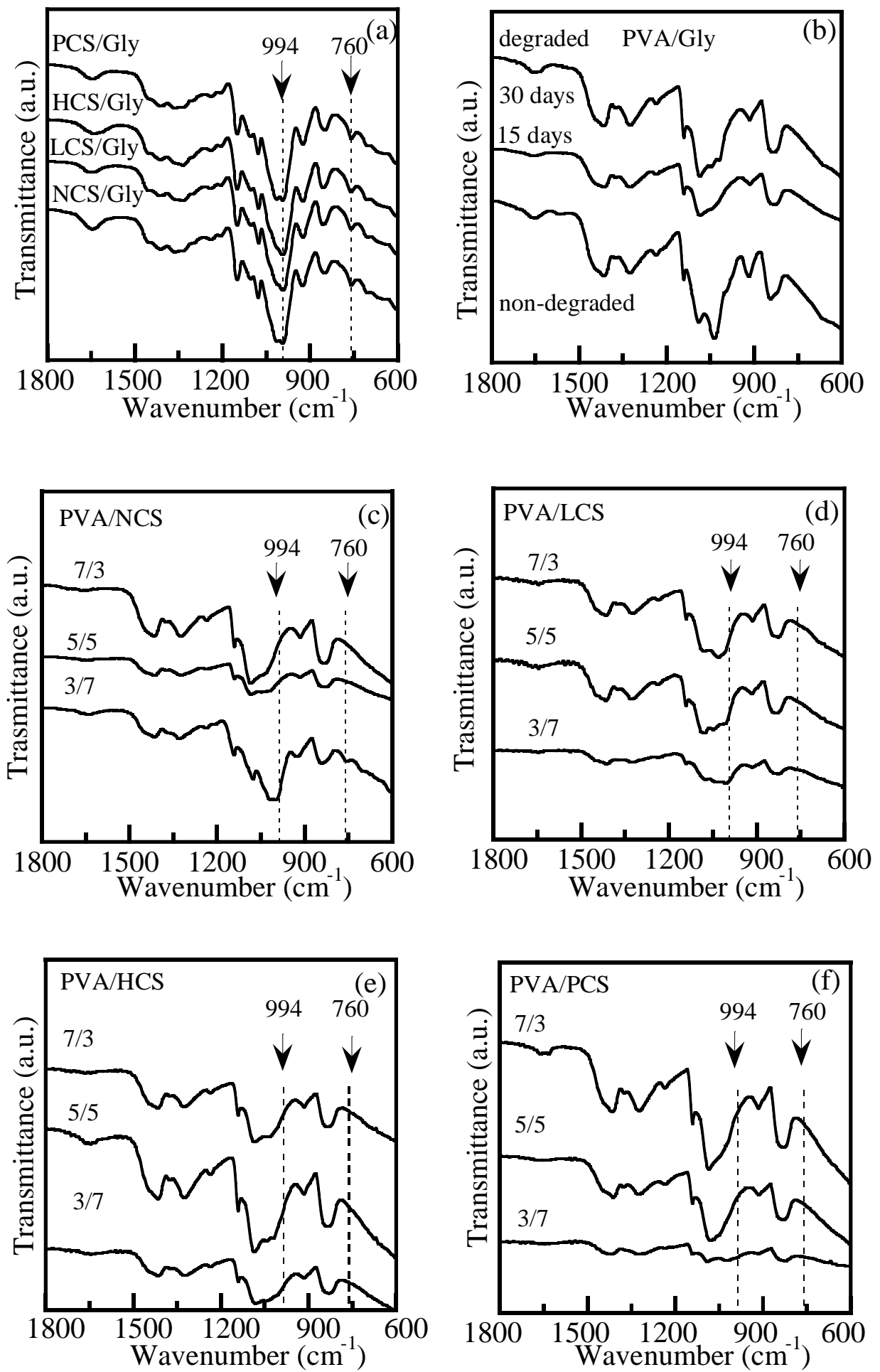

Figure 4. The FTIR spectra were obtained from (a) non-degraded starch/Gly films, (b) nondegraded PVA/Gly film and degraded PVA/Gly films by burial in soil for 15 and 30 days, (c) PVA/NCS/Gly, (d) PVA/LCS/Gly, (e) PVA/HCS/Gly, and (f) PVA/PCS/Gly films degraded by burial in soil for 30 days. Ratios of PVA/starch are indicated. 
The FTIR spectra of other degraded PVA/starch/Gly blend films show no indication of residual starch after burial in soil for 30 days. The characteristic peaks of starch at 994 and $760 \mathrm{~cm}^{-1}$ were absent in 5/5 and 7/3 PVA/starch blends. This result indicates the complete degradation of the starch in these films. The close similarity of the spectra of degraded blends and those of non-degraded PVA suggests that microorganisms had degraded all the starch, but not the PVA. ${ }^{14}$

\subsection{Thermal analysis of the films}

The non-degraded and degraded films were analyzed by DSC. The data of melting temperature $\left(T_{\mathrm{m}}\right)$, enthalpy of fusion $\left(\Delta H_{\mathrm{f}}\right)$, and degree of crystallinity $\left(X_{\mathrm{c}}\right)$ of non-degraded and degraded films buried in soil for 30 days are shown in Table 2. The degree of crystallinity $\left(X_{\mathrm{c}}\right)$ of non-degraded films was calculated using the following equation: ${ }^{17}$

$$
X_{c}=\Delta H_{f} /\left(\Delta H_{f}^{0} w\right) \times 100
$$

where $\Delta H_{\mathrm{f}}$ is the apparent enthalpy of fusion of PVA/Gly and PVA/starch/Gly blend films, $w$ is the weight fraction of PVA, and $\Delta H_{f}^{0}$ is the enthalpy of fusion of $100 \%$ crystalline PVA $(141.932 \mathrm{~J} / \mathrm{g}) .{ }^{56}$ The degree of crystallinity of degraded films was calculated using the same equation where $w$ was equal to 1 .

Regarding non-degraded films, both $T_{\mathrm{m}}$ and $\Delta H_{\mathrm{f}}$ of PVA/starch/Gly were lower than those of PVA/Gly. This result implies the insertion of starch chains to the crystalline site of PVA. The $T_{\mathrm{m}}$ of non-degraded films increased with the content of PVA. The $T_{\mathrm{m}}$ of all degraded films was much higher than the $T_{\mathrm{m}}$ of non-degraded films ${ }^{57}$ of all compositions. Although some amorphous phase of PVA, together with glycerol and starch, was consumed during biodegradation, ${ }^{14}$ the crystalline structures of PVA remained giving rise to the higher values of $T_{\mathrm{m}}{ }^{57}$ 
Table 2. The melting temperature $\left(T_{\mathrm{m}}\right)$, enthalpy of fusion $\left(\Delta H_{\mathrm{f}}\right)$ and degree of crystallinity $\left(X_{c}\right)$ of non-degraded and degraded PVA/Gly and PVA/starch/Gly films buried in soil for 30 days were obtained from the $2^{\text {nd }}$ DSC heating scan.

\begin{tabular}{lccc|ccc}
\hline \multicolumn{1}{c}{ Sample } & \multicolumn{3}{c}{ Non-degraded films } & \multicolumn{3}{c}{ Degraded films } \\
\cline { 2 - 7 } & $T_{\mathrm{m}}\left({ }^{\circ} \mathrm{C}\right)$ & $\Delta H_{\mathrm{f}}\left(\mathrm{J} \mathrm{g}^{-1}\right)$ & $X_{c}(\%)$ & $T_{\mathrm{m}}\left({ }^{\circ} \mathrm{C}\right)$ & $\Delta H_{\mathrm{f}}\left(\mathrm{J} \mathrm{g}^{-1}\right)$ & $X_{c}^{\mathrm{a}}(\%)$ \\
\hline PVA/Gly & 205.7 & 53.92 & 49.39 & 232.8 & 88.92 & 62.65 \\
\hline 3PVA/7NCS/Gly & 193.0 & 11.54 & 35.23 & 226.7 & 42.16 & - \\
3PVA/7LCS/Gly & 190.4 & 10.39 & 31.72 & 223.1 & 45.88 & 32.32 \\
3PVA/7HCS/Gly & 180.6 & 9.50 & 29.00 & 222.9 & 63.65 & 44.84 \\
3PVA/7PCS/Gly & 195.0 & 11.65 & 35.57 & 231.6 & 69.35 & 48.86 \\
\hline 5PVA/5NCS/Gly & 198.8 & 20.80 & 38.10 & 229.5 & 75.14 & 52.94 \\
5PVA/5LCS/Gly & 194.2 & 20.92 & 38.32 & 226.8 & 69.95 & 49.28 \\
5PVA/5HCS/Gly & 189.0 & 19.53 & 35.78 & 226.0 & 68.17 & 48.03 \\
5PVA/5PCS/Gly & 201.0 & 22.06 & 40.41 & 229.6 & 76.57 & 53.95 \\
\hline 7PVA/3NCS/Gly & 200.4 & 32.96 & 43.13 & 230.1 & 78.99 & 55.65 \\
7PVA/3LCS/Gly & 197.5 & 37.58 & 40.76 & 231.8 & 72.32 & 50.95 \\
7PVA/3HCS/Gly & 193.9 & 31.15 & 40.17 & 226.8 & 73.78 & 51.98 \\
\hline TPVA-3PCS/Gly & 201.2 & 34.77 & 45.50 & 232.2 & 79.05 & 55.69 \\
\hline
\end{tabular}

a The $X_{\mathrm{c}}$ of 3PVA/7NCS/Gly was not calculated due to the presence of starch confirmed by FTIR.

The $\Delta H_{\mathrm{f}}$ of non-degraded and degraded PVA/starch/Gly films showed similar trends to the $T_{\mathrm{m}}$. The non-degraded PVA/starch/Gly films exhibited lower $\Delta H_{\mathrm{f}}$ values due to the plasticizing effect of glycerol. At higher contents of PVA, $\Delta H_{\mathrm{f}}$ increased $^{17}$ in a manner consistent with increase in $T_{\mathrm{m}}$. The $\Delta H_{\mathrm{f}}$ of degraded films were higher than those of nondegraded films. ${ }^{57}$ The high values of $T_{\mathrm{m}}$ and $\Delta H_{\mathrm{f}}$ for these degraded films were a result of the 
hydrolysis and reorganization of PVA that occurred during the biodegradation process. ${ }^{14,57}$ Huang et al. reported that the hydrolysis of starch took place first during biodegradation, followed by the consumption of a part of the amorphous phase of PVA. ${ }^{14,58}$ The higher $T_{\mathrm{m}}$ and $\Delta H_{\mathrm{f}}$ of degraded films were due to the crystalline nature of the regions that remained after biodegradation.

The degree of crystallinity $\left(X_{\mathrm{c}}\right)$ values of degraded films were higher compared to the non-degraded films, an observation consistent with a previous study that indicated that biodegradation in semi-crystalline polymers occurs predominantly in their amorphous regions. ${ }^{59}$

\subsection{Morphology of the films}

Images of cryo-fracture surfaces of pure PVA and PVA/Gly films are presented in Figure S3 in the Supporting Information. Both materials exhibited rough surfaces. In the micrographs of cryo-fracture surfaces of PVA/starch/Gly blend films (Figure 5), starch granules are not present nor voids in the fracture surface. This morphology could be attributed to hydrogen bonding between the $-\mathrm{OH}$ groups of PVA and the $-\mathrm{OH}$ groups of starch. Among the PVA/NCS/Gly films (Figure 5(a)-(c)), the fracture surfaces of 3PVA/7NCS/Gly and 5PVA/5NCS/Gly are less rough than 7PVA/3NCS/Gly due to the high amount of PVA in the 7/3 blend. The rough surface of 7PVA/3NCS/Gly indicates the incompatibility of the polymers and the formation of two phases: a PVA-rich phase and a starch-rich phase. ${ }^{17}$ The surfaces of PVA/LCS/Gly films (Figure 5(d)-(f)) were also rougher at higher contents of PVA.

The incompatibility between the polymers is also evident in images of the fracture surfaces of 5PVA/5HCS/Gly (Figure 5(h)) and 7PVA/3HCS/Gly (Figure 5(i)). Both blends exhibit phase separation and two layers are visible in the fractures of these two films. We consider the lower layer (the bottom side) to comprise a continuous PVA-rich phase 
containing a dispersed phase of starch droplets, which are indicated by arrows in Figure 5(i). The upper starch-rich and lower PVA-rich phases are evenly-layered or laminated.

This explanation of the morphology is supported by the results of the swelling test in water (Figure S4 and S5 in the Supporting Information). All starch/Gly (Figure S4(a)-(d)) films swelled within 24 hours but PVA/Gly film (Figure S4(e)) showed less swelling than the starch films. The PVA/Gly film remained clear, whereas all the starch/Gly films became turbid. The turbidity of the PVA/starch/Gly blend samples (Figure S5) was likely caused by the presence of starch in the PVA-rich phase of the films, which did not completely dissolve during the test

Phase separation is also apparent in the images of the fracture surfaces of 5PVA/5PCS/Gly (Figure 5(k)) and 7PVA/3PCS/Gly (Figure 5(l)) with a lower layer of PVArich phase and an upper layer of PCS-rich phase. The interface between the two phases is uneven. The phase separation visible in the SEM micrograph of 7PVA/3PCS/Gly was confirmed by the swelling test. Separated layers are visible in the photograph of the swollen film sample of 7PVA/3PCS/Gly (Figure S5(d)) but the phases of the 5PVA/5PCS/Gly film (Figure S5(c)) did not clearly separate during the test. The turbidity of the two separated layers in the image of 7PVA/3PCS/Gly suggests that PVA and PCS phases were present in both layers. None of the other PVA/starch/Gly blend films delaminated during swelling. Phase separation has also been reported in the blend films of PVA/corn $\operatorname{starch}^{2}$ and PVA/pea sarch. ${ }^{17}$ 

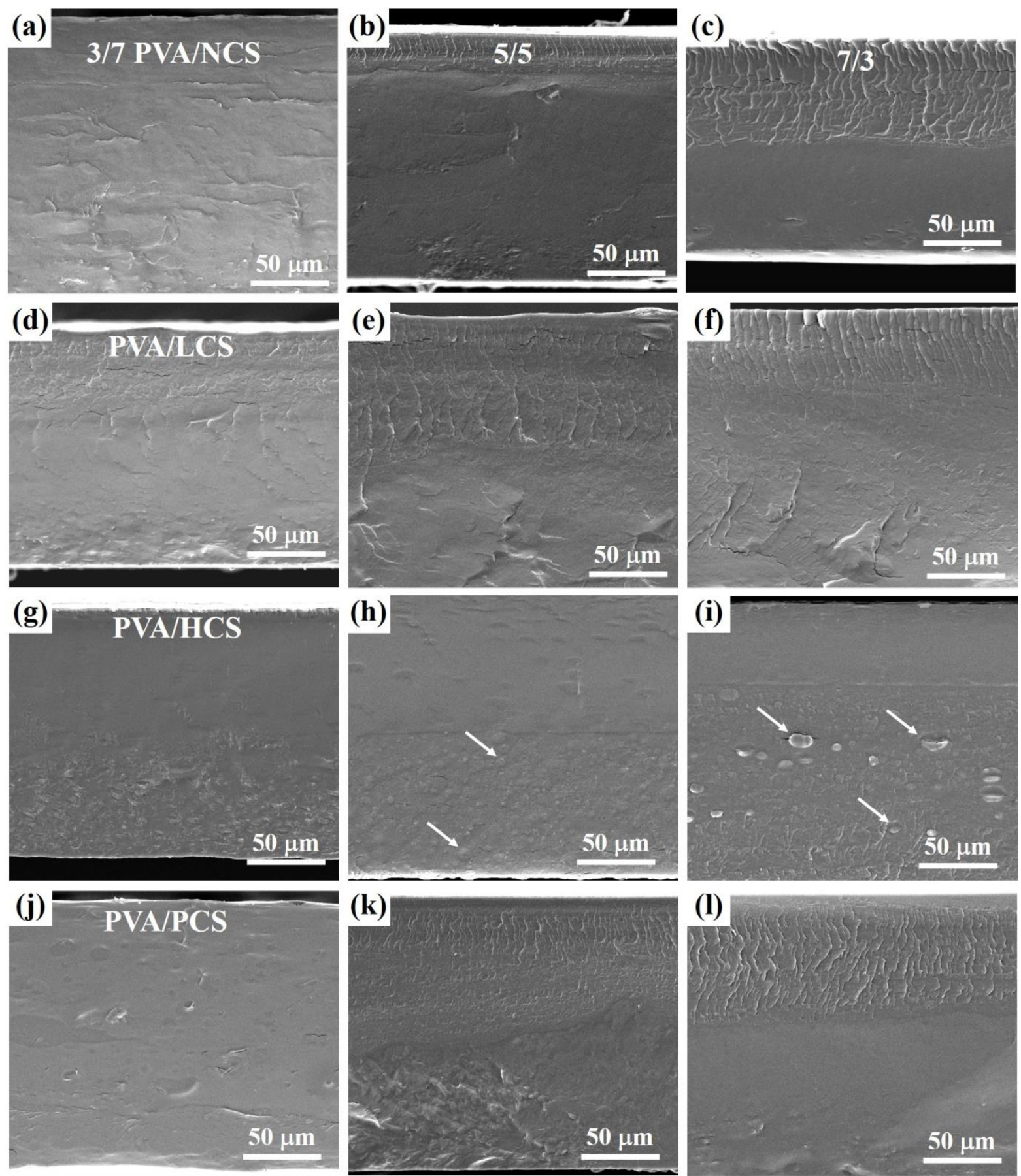

Figure 5. SEM micrographs show the cryo-fracture surfaces of (a)-(c) PVA/NCS/Gly, (d)-(f) PVA/LCS/Gly, (g)-(i) PVA/HCS/Gly, and (j)-(l) PVA/PCS/Gly blend films. Ratios of PVA/starch are indicated. The bottom surface was in contact with the polystyrene plate during casting. 
In a previous morphological study of PVA/starch blend films, the immiscibility of starch and PVA phases was indicated by the distribution of starch in the PVA matrix ${ }^{55}$ In this work, the slight surface degradation visible in the SEM image of PVA/Gly after 30 days in soil (Figure S6(b) in the Supporting Information) was consistent with the data from the soil burial test (Figure S1), in which PVA/Gly lost the least weight. In PVA/starch/Gly films subjected to biodegradation, SEM micrographs show that a PVA phase remained but not a starch phase after15 days (Figure S7 in the Supporting Information) and 30 days (Figure 6) in soil. The phase compositions of biodegraded films were consistent with data obtained from FTIR analysis, the exception for 3PVA/7NCS/Gly, 3PVA/7LCS/Gly, and 3PVA/7HCS/Gly films (15 days in soil) (Figure S2(a) and (c)) and 3PVA/7NCS/Gly film (30 days in soil) (Figure 4(c)).

After 30 days in soil, 5PVA/5NCS/Gly (Figure 7(a)) and 7PVA/3NCS/Gly (Figure 7b)) presented a co-continuous phase of interpenetrated PVA and NCS phases. The cocontinuous phase was a result of the immiscibility of the blend and in 7PVA/3NCS/Gly, the major co-continuous phase was combined with a minor droplet phase. In degraded 5PVA/5LCS/Gly and 7PVA/3LCS/Gly films (Figure 7(c)-(d)), the co-continuous phase is not as well defined as the co-continuous phases in the degraded blend films of 5PVA/5NCS/Gly and 7PVA/3NCS/Gly (Figure 7(a)-(b)). After 30 days in soil, 5PVA/5HCS/Gly (Figure 6(h) and 7(e)) and 7PVA/3HCS/Gly (Figure 6(i) and 7(f)) showed PVA matrices containing pores derived from the droplet phase of starch (Figure 5(h)-(i)) that was lost during biodegradation. 

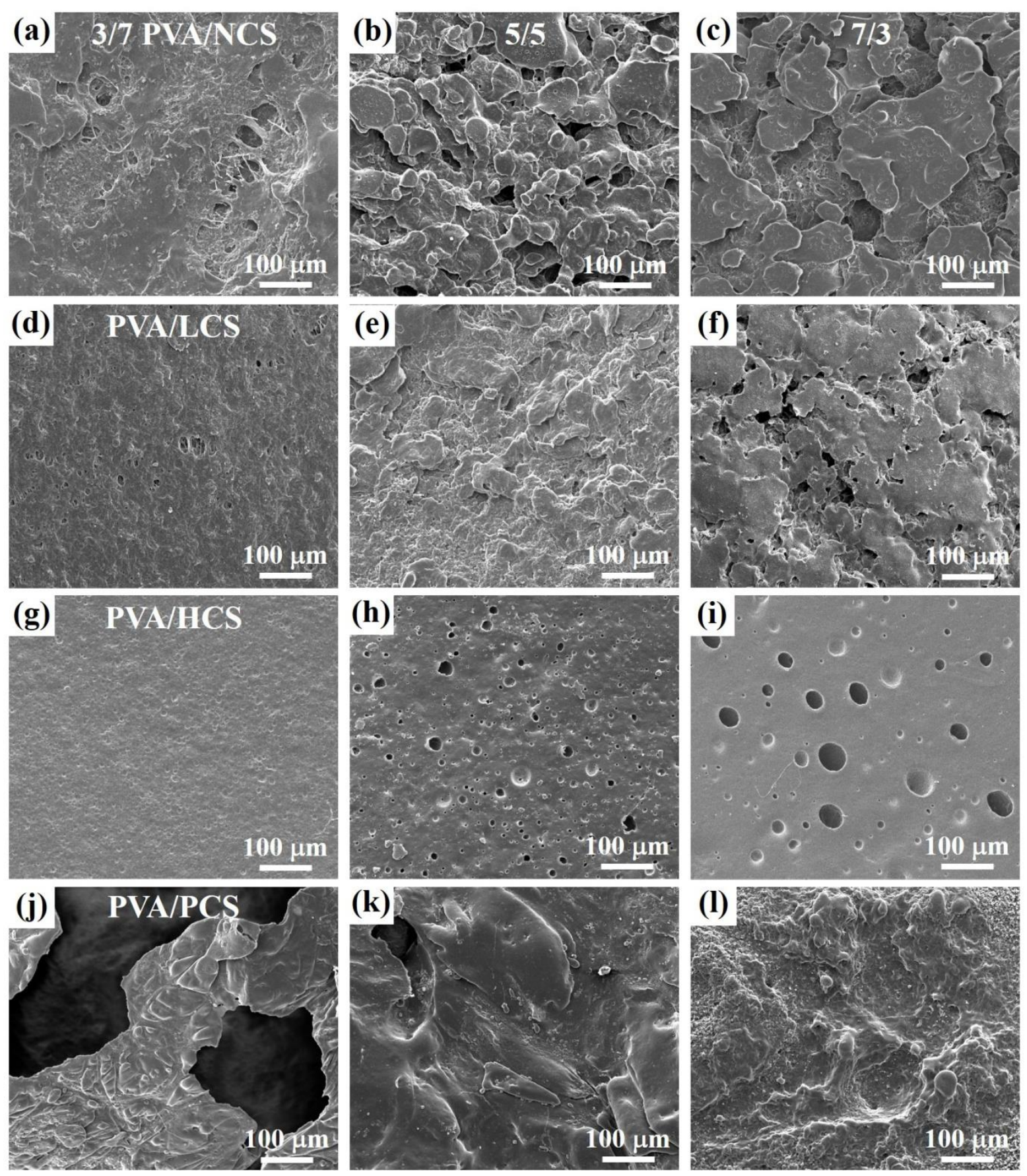

Figure 6. SEM micrographs show top surfaces of (a)-(c) PVA/NCS/Gly, (d)-(f)

PVA/LCS/Gly, (g)-(i) PVA/HCS/Gly, and (j)-(l) PVA/PCS/Gly films after burial in soil for 30 days. 

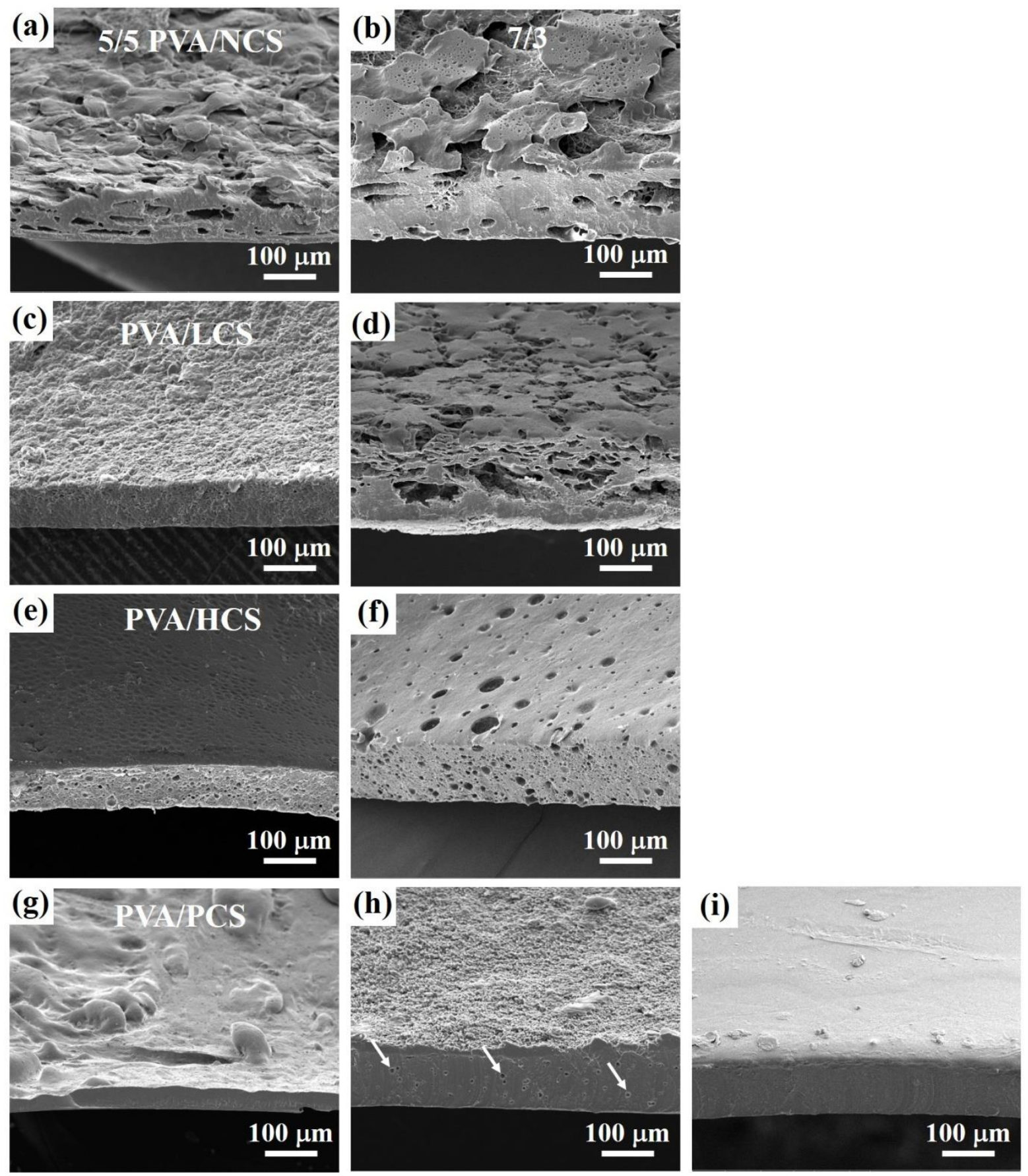

Figure 7. SEM micrographs show edges and top surfaces of degraded films after burial in soil for 30 days: (a)-(b) PVA/NCS/Gly, (c)-(d) PVA/LCS/Gly, (e)-(f) PVA/HCS/Gly, (g)-(h) PVA/PCS/Gly blends and (i) PVA/Gly film as indicated. Blend ratios are indicated at the top of the columns. 
After 30 days in soil, the degraded 3PVA/7PCS/Gly blend film (Figure 6(j)) presented large holes in the PVA matrix. This morphology was not unexpected. We discussion in section 3.2 the formation during film preparation of a visible fraction consisting of large gel particles and these swollen starch gel particles would be completely degraded in soil. However, in the degraded samples of 5PVA/5PCS/Gly (Figure 6(k) and Figure 7(g)) and 7PVA/3PCS/Gly (Figure 6(l) and Figure 7(h)), the PVA phase remaining after biodegradation of the starch-rich layer presented an uneven layer surface without the large holes present in 3PVA/7PCS/Gly (Figure 6(j)). This morphology is consistent with the morphology of non-degraded samples of 5PVA/5PCS/Gly and 7PVA/3PCS/Gly, which exhibited phase-separation with an uneven boundary at the interface. In the lower layer of a degraded 7PVA/3PCS/Gly (Figure S8(b) in the Supporting Information), large pores are visible which derives from the loss of the gel fraction of the PCS phase. The PVA phase in degraded 7PVA/3PCS/Gly (Figure 7(h)) presented a matrix with small pores, indicated by arrows. These pores were left behind after the loss of the starch droplet phase derived from the soluble fraction of PCS.

The SEM images of the edges of all degraded PVA/starch/Gly blend films (Figure 7) confirm that the surface of the bottom side was a PVA-rich phase, whereas the surface of the air was a starch-rich phase. PVA tended to sink to the bottom and starch tended to float up to the top of the films. As native starch had the highest $\eta_{\text {app }}$, the morphology of the remaining PVA phase in degraded PVA/NCS/Gly blend films resembled a co-continuous phase (Figure 7(a) and (b)). Since HCS had the lowest $\eta_{\text {app, }}$, the morphology of the PVA/HCS/Gly blend films (Figure 5(g)-(i)) consisted of two layers. Because the $\eta_{\text {app }}$ of HCS in glycerol solution is similar to that of PVA, PVA tended to settle to the bottom and HCS floated to the top. The droplets present in the cross-section of the films (Figure 5(h) and (i)) were starch, which was confirmed by the presence of small holes in the remaining PVA phase after biodegradation. 
After considering the results from FTIR analysis of non-degraded blend films in section 3.4 and the SEM micrographs from morphological study, we concluded that the FTIR assignments obtained from the air side (Table S2) indicted the PVA-rich phase, whereas those obtained from the bottom side (Table S3) indicated the starch-rich phase. During ATRFTIR measurement, the film was pressed by a concave stainless tip to ensure good contact with the diamond crystal. This procedure makes the film thinner and the incident beams could better penetrate the thin film. It was reported that the effectiveness in ATR-FTIR spectroscopic imaging depends upon the wavelength, angle of incidence and the depth of penetration of the incoming light beam. ${ }^{60}$

\subsection{Mechanical properties of the films}

The one-way analysis of variance (ANOVA) results for tensile strength at 95\% confidence interval showed that there was a significant effect of PVA content on the tensile strength of all PVA/starch blend films ( $\mathrm{p}<0.05)$, except 3/7 and 5/5 PVA/LCS films ( $>00.05)$.

The ANOVA results for elongation at break at $95 \%$ confidence interval also showed that there was a significant effect of PVA content for all PVA/starch films $(p<0.05)$, except 5/5 and 7/3 PVA/NCS, and 3/7 and 7/3 PVA/HCS blends ( $>>0.05)$.

Apart from the elongation at break of NCS/Gly film, values for tensile strength and elongation at break of all the starch/Gly films were low. ${ }^{17}$ This exception to the general behavior of all starch/Gly films was due to the long molecular chains of NCS and is consistent with the viscosity of NCS, which had the highest $\eta_{\text {app }}$ values of all the starches (Figure 2(a)).

PVA/Gly film exhibited good mechanical properties due to its flexible $\mathrm{C}-\mathrm{C}$ backbone and abundance of hydroxyl groups. ${ }^{61}$ It showed the highest tensile strength at $\approx 39 \mathrm{MPa}$ (Figure $8(a)$ ) and the highest elongation at break at $\approx 615 \%$ (Figure $8(b)$ ). 

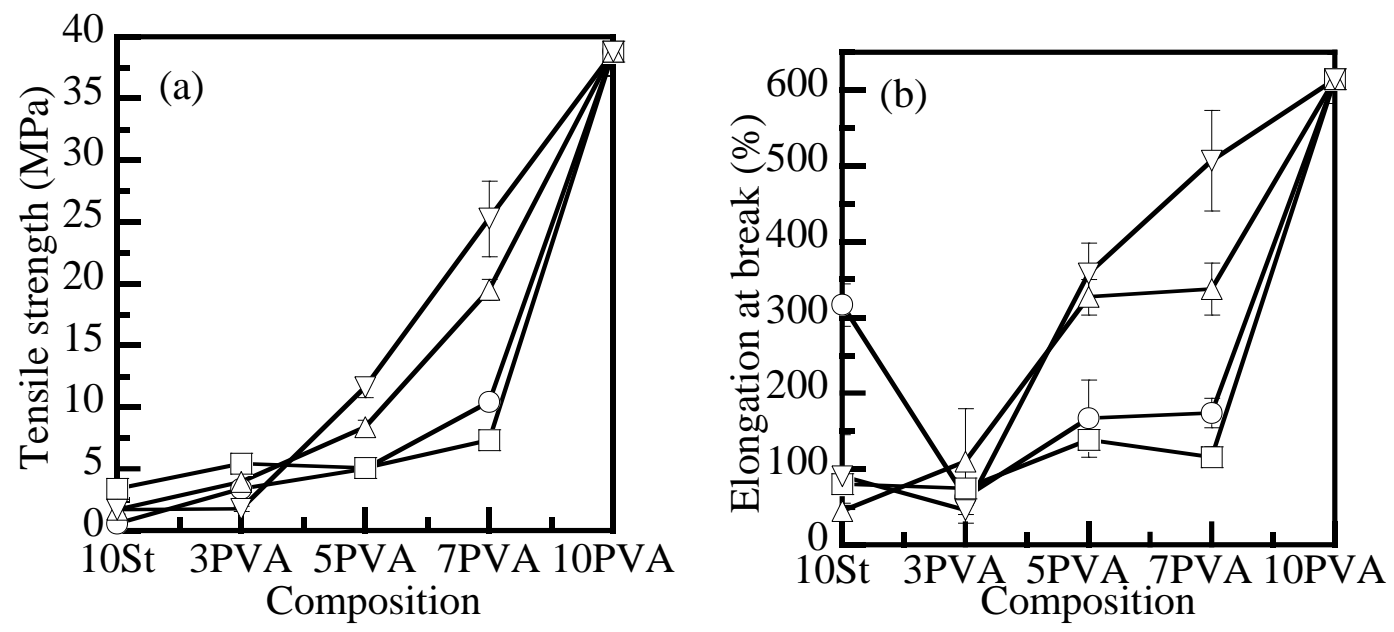

Figure 8. Effect of PVA content on tensile strength (a) and elongation at break (b) of starch/Gly, PVA/starch/Gly blend, and PVA/Gly films: (O) PVA/NCS, ( $\square$ ) PVA/LCS, ( $\triangle$ ) PVA/HCS, and ( $\nabla)$ PVA/PCS. 10St denotes a plasticized starch film without PVA.

The tensile strength and elongation at break of the PVA/starch/Gly blend films increased as the amount of PVA increased. ${ }^{10}$ The improvement in the tensile behavior of PVA/starch/Gly was attributed to the formation of hydrogen bonds between the -OH groups of PVA and the -OH groups of starch. ${ }^{3}$ Among the PVA/starch/Gly blend films, 7PVA/3starch/Gly blends showed the highest tensile strength. The poor mechanical properties of starch/Gly films were improved by blending with PVA. ${ }^{36}$ PCS blended with PVA at a PVA/starch ratio of $7 / 3$ showed the highest tensile strength $(\approx 25 \mathrm{MPa})$ and elongation at break $(\approx 500 \%)$ of all the PVA/starch blends. In summary, 7PVA/3PCS/Gly exhibited performance characteristics in line with those seen in polymers widely used for flexible packaging applications. ${ }^{62}$ The PVA/HCS/Gly blends showed higher tensile strength and elongation at break than PVA/NCS/Gly blends and the PVA/LCS/Gly films exhibited the lowest tensile strength and elongation at break.

The SEM image of degraded PVA/Gly (Figure 7(i)) presents a dense single phase layer. This morphology supports the results of tensile strength measurement, in which 
PVA/Gly films yielded the highest values (Figure 8(a)). In the 7PVA/3PCS/Gly blend (Figure 7(h)), the small droplets embedded in the major phase PVA produced tensile strength lower than that of PVA/Gly film but higher than that of PVA/HCS/Gly blend films (Figure 8(a)). The more well-defined co-continuous phase of PVA in 7PVA/3NCS/Gly was the reason that the tensile strength of this blend was higher than that of 7PVA/3LCS/Gly. Higher tensile strength was the result of stronger interactions within the blend when higher amounts of PVA were present. ${ }^{8}$ Therefore, the mechanical properties of the prepared PVA/starch/Gly films were significantly affected by the morphologies of PVA phase of the films. The significance of the effect at $70 \mathrm{wt} \%$ PVA in the blends could be classified in the following order: dense phase $(\mathrm{PVA} / \mathrm{Gly})>$ droplet phase $(\mathrm{PVA} / \mathrm{PCS} / \mathrm{Gly}>\mathrm{PVA} / \mathrm{HCS} / \mathrm{Gly})>$ welldefined co-continuous phase (PVA/NCS/Gly) > poorly-defined co-continuous phase (PVA/LCS/Gly).

\section{Conclusions}

A series of glycerol plasticized PVA/starch blends were prepared via solution casting to enable a systematic evaluation of their structural, morphological, mechanical and thermal properties. The inherent incompatibility between the two phases (PVA/starch) gives rise to a variety of morphological features depending on the chemical nature of the starch phase (native, low oxidized, high-oxidized, and pre-gelatinized). To that end, the systems comprising $70 \mathrm{wt} \%$ PVA adopt morphological characteristics that can be described as droplet phase (PVA/PCS/Gly and PVA/HCS/Gly), well-defined co-continuous phase (PVA/NCS/Gly) and poorly-defined co-continuous phase (PVA/LCS/Gly). Interestingly, the morphology of those systems seem to play a significant role in defining their mechanical properties (in terms of tensile strength and elongation at break), with the droplet phases exhibiting improved behavior compared to the co-continuous phases. Burial tests demonstrated the complete decomposition/removal of starch and glycerol over a period of 30 
days, while the PVA phase that was left behind appears to possess higher levels of crystallinity, possibly indicating that the amorphous phase of PVA is more susceptive to biodegradation mechanisms.

\section{Acknowledgements}

This work is supported by the Faculty of Science Research Fund (2558, contract number 158007), Prince of Songkla University. The authors would like to thank Mr. Thomas Coyne for assistance with English. 


\section{References}

1. Ramaraj, B. J. Appl. Polym. Sci. 2007, 103, 909-916.

2. Sreekumar, P. A., Al-Harthi, M. A. and De, S. K. J. Appl. Polym. Sci. 2012, 123, 135 142.

3. Siddaraamaiah, Raj, B. and Somashekar, R. J. Appl. Polym. Sci. 2004, 91, 630-635.

4. Lenz, R. W. Adv. Polym. Sci. 1993, 107, 1-40.

5. Ramaraj, B. Polym.-Plast. Technol. Eng. 2006, 45, 1227-1231.

6. Gartiser, S., Wallrabenstein, M. and Stiene, G. J. Environ. Polym. Degrad. 1998, 6, $159-173$.

7. Corti, A., Cinelli, P., D’Antone, S., Kenaway, E. and Solaro, R. Macromol. Chem. Phys. 2002, 203, 1526-1531.

8. Wang, W., Zhang, H., Jia, R., Dai, Y., Dong, H., Hou, H. and Guo, Q. Food Hydrocoll. 2018, 79, 534-543.

9. Chen, Y., Cao, X., Chang, P. R. and Huneault, M. A. Carbohydr. Polym. 2008, 73, 817.

10. Gou, G., Zhang, C., Du, Z., Zou, W. and Li, H. J. Polym. Environ. 2014, DOI $10.1007 / \mathrm{s} 10924-014-0682-7$.

11. Mao, L., Imam, S., Gordon, S., Cinelli, P. and Chiellini, E. J. Polym. Environ. 2000, $8,205-211$.

12. Yoon, S. D. J. Agric. Food Chem. 2014, 62, 1755-1764.

13. Luo, X., Li, J. and Lin, X. Carbohydr. Polym. 2012, 90, 1595-1600.

14. Jayasekara, R., Harding, I., Bowater, I., Chistie, G. B. Y. and Lonergan, G. T. J. Polym. Environ. 2003, 11, 49-56. 
15. Jayasekara, R., Harding, I. Bowater, I., Christie, G. B. Y. and Lonergan, G. T. Polym. Test. 2004, 23, 17-27.

16. Elizondo, N. J., Sobral, P. J. A. and Menegalli, F. C. Carbohydr. Polym. 2009, 75, $592-598$.

17. Cano, A., Fortunati, E., Cháfer, M., Kenny, J. M., Chiralt, A. and González-Martínez, C. Food Hydrocoll. 2015, 48, 84-93.

18. Liu, Y., Lv, X. C., Hu, X., Shan, Z. H. and Zhu, P. X. Carbohydr. Polym. 2010, 81, 911-918.

19. Kuakpetoon, D. and Wang, Y. J. Starch/Stärke. 2001, 53, 211-218.

20. Sangseethong, K., Lertphanich, S. and Sriroth, K. Starch/Stärke 2009, 61, 92-100.

21. Sangseethong, K., Termvejsayanon, N. and Sriroth, K. Carbohydr. Polym. 2010, 82, 446-453.

22. Garrido, L. H., Schnitzler, E., Zortéa, M. E. B., Rocha, T. de S. and Demiate, I. M. J. Food Sci. Technol. 2014, 51(10), 2640-2647.

23. Palma-Rodríguez, H. M., Aguirre-Álvarez, G., Chavarría-Hernández, N., Rodríguez-Hernández, A. I., Bello-Pérez, L. A. and Vargas-Torres, A. Starch/Stärke 2012, 64, 882-889.

24. Alcázar-Alay, S. C. and Meireles, M. A. A. Food Sci. Technol. 2015, 35(2), 215-236.

25. Chiu, C. W.; Solarek, D. In Starch Chemistry and Technology $3^{\text {rd }}$ Edition; BeMiller, J.; Whistler, R., Eds.; Academic Press: New York, 2009, Chapter 17.

26. Wijanarka, A.; Sudago, T.; Harmayani, E.; Marsono, Y. Am. J. Food Technol. 2017, 12, 178-185, DOI: 10.3923/ajft.2017.178.185.

27. Anwar, E., Khotimah, H. and Yanuar, A. J. Med. Sci. 2006, 6, 923-929.

28. Park, H. R., Chough, H. R., Yun, Y. H. and Yoon, S. D. J. Polym. Environ. 2005, 13(4), 375-382. 
29. Chalét, C. M., Halley, P. J. and Truss, R. W. Polym. Degrad. Stab. 2012, 97, 19301939.

30. Wu, S. Polymer 1985, 26(12), 1855-1863.

31. Machiels, A. G. C., Denys, K. F. J., Van Dam, J. and Posthuma de Boer, A. Polym. Eng. Sci. 1996, 36, 2451-2466.

32. Nir, M. M., Ram, A. and Miltz, J. Polym. Eng. Sci. 1995, 35, 1878-1883.

33. Xie, H. Q., Xu, J. and Zhou, S. Polymer 1991, 32(1), 95-102.

34. Vashishtha, S. R., Chand, N. and Hashmi, S. A. R. Indian J. Chem. Techn. 2002, 9, 316-323.

35. Willemse, R. C., Posthuma de Boer, A., van Dam, J. and Gotsis, A. D. Polymer 1998, 39(24), 5879-5887.

36. Liu, Z.; Feng, Y.; Yi, X. S. J. Appl. Polym. Sci. 1999, 74, 2667-2673.

37. Julapong, K., Boonsuk, P., Chaibundit, C. and Chantarak, S. Int. J. Biol. Macromol. 2019, 137, 521-527.

38. Rahman, W. A. W. A., Sin, L. T., Rahmat, A. R. and Samad, A. A. Carbohyr. Polym. 2010, $81,805-810$.

39. Trifol, J., Drongelen, M. V., Clegg, F., Plackett, D., Szabo, P. and Daugaard, A. E. J. Appl. Polym. Sci. 2019, DOI: 10.1002/APP.47486.

40. Fortunati, E., Yang, W., Luzi, F., Kenny, J., Torre, L. and Puglia, D. Eur. Polym. J. 2016, 80, 295-316.

41. Klein, B., Vanier, N. L., Moomand, K., Pinto, V. Z., Colussi, R., Zavareze, E.da R. and Dias, A. R. G. Food Chem. 2014, 155, 167-173.

42. Majzoobi, M., Radi, M., Farahnaky, A., Jamalian, J., Tongdang, T. and Mesbahi, Gh. J. Agr. Sci. Tech. 2011, 13, 193-202.

43. Dong, V., Xie, J., Liu, Q., Li, D. and Hu, P. Polym. Eng. Sci. 2014, 54, 2449-2454. 
44. Nurul I, M., Mohd. Azemi, B. M. N. and Manan, D. M. A. Food Chem. 1999, 64, 501-505.

45. Holdsworth, S. D. J. Texture Stud. 1971, 2, 393-418.

46. Vanire, N. L., Halal, S. L. M. E., Dias, A. R. G. and Zavareze, E. da R. Food Chem. 2017, 221, 1546-1559.

47. Sánchez-Rivera, M. M., Garciá-Suárez, F. J. L., Velázquez del Valle, M., GutierrezMeraz, F. and Bello-Pérez, L. A. Carbohydr. Polym. 2005, 62, 50-56.

48. White, E. E. B., Chellamuthu, M. and Rothstein, J. P. Rheo. Acta. 2010, 49, 119-129.

49. Valencia, G. A., Henao, A. C. A. and Zapata, R. A.V. J. Polym. Eng. 2013, 33(2), $141-148$.

50. Kim, D. and Yoo, B. Food Sci. Biotechnol. 2014, 23(3), 787-790.

51. Chamberlain, E. K., Pao, M. A. and Cohen, C. Int. J. Food Prop. 1999, 2(1), 63-77.

52. Nagara, Y., Nakano, T., Okamoto, Y., Gotoh, Y. and Nagura, M. Polymer 2001, 42, 9679-9686.

53. Cael, J. J., Koening, J. L. and Blackwell, J. Biopolymers 1975, 14, 1885-1903.

54. Kačuráková. M. and Mathlouthi, M. Carbohydr. Res. 1996, 284, 145-157.

55. Azahari, N. A., Othman, N. and Ismail, H. J. J. Phys. Sci. 2011, 22(2), 15-31.

56. Nisho,Y., Haratani, T., Takahashi, T. and Manley, R. S. J. Macromolecules 1989, 22, $2547-2549$.

57. Tudorachi, N., Cascaval, C. N., Rusu, M. and Pruteanu, M. Polym. Test. 2000, 19, 785-799.

58. Huang, S. J.; Ho, M. T.; Koenig, M. F.; Cameron, J. A. In Biodegradable Plastics and Polymers; Doi, Y.; Fukudau, K., Eds.; Elsevier: Amsterdam. 1993; Vol. 12.

59. Iwata, T. and Doi, Y. Polym. Int. 2002, 51, 852-858. 
60. Song, C. L. and Kazarian S. G. Analyst 2019, 144, 2954-2964.

61. Tian, H., Yan, J., Rajula, A. V., Xiang, A. and Luo, X. Int. J. Biol. Macromol. 2017, $96,518-523$.

62. Morris, B. A. In The Science and Technology of Flexible Packaging: Multilayer films from Resin and Process to End Use, Elsevier: Oxford 2017, Chapter 4. 